Lunar Influence on Atmospheric Ozone

EVIDENCE has been put forward for a lunar influence on different geophysical data such as rainfall ${ }^{1,2}$ freezing nuclei counts $^{3}$, radar meteor ${ }^{4}$, geomagnetic disturbances ${ }^{5}$, twilight sky brightness ${ }^{7}$, atmospheric ozone ${ }^{6}$, and sky light polarization $^{8}$. I have analysed ozone data for twelve stations, six from each hemisphere, and the results are reported here. Ozone data used are those published by the World Meteorological Organization in cooperation with the Meteorological Service of Canada.

\begin{tabular}{rlccc}
\hline \multicolumn{4}{c}{ Table 1 } & Daily Total Ozone Data Utilized \\
\cline { 1 - 4 } No. & Station & Latitude & Longitude & Period of record \\
1 & Aarhus & $56 \mathrm{~N}$ & $10 \mathrm{E}$ & Jan. 1960-Dec. 1967 \\
2 & Goose Bay & $53 \mathrm{~N}$ & $60 \mathrm{~W}$ & Jan. 1962-Dec. 1967 \\
3 & Arosa & $46 \mathrm{~N}$ & $9 \mathrm{E}$ & Jan. 1960-Dec. 1967 \\
4 & Toronto & $44 \mathrm{~N}$ & $79 \mathrm{~W}$ & Jan. 1960-Dec. 1967 \\
5 & Tateno & $36 \mathrm{~N}$ & $140 \mathrm{E}$ & Jan. 1960-Dec. 1967 \\
6 & Ahmedabad & $23 \mathrm{~N}$ & $72 \mathrm{E}$ & Jan. 1960-Dec. 1967 \\
7 & Kodaikanal & $10 \mathrm{~N}$ & $77 \mathrm{E}$ & Jan. 1960-Dec. 1967 \\
8 & Gan & $0.4 \mathrm{~S}$ & $73 \mathrm{E}$ & Jan. 1964-Oct. 1967 \\
9 & Huancayo & $12 \mathrm{~S}$ & $75 \mathrm{~W}$ & Feb. 1964-Dec. 1967 \\
10 & Brisbane & $27 \mathrm{~S}$ & $153 \mathrm{E}$ & Jan. 1960-Dec. 1967 \\
11 & Aspendale & $38 \mathrm{~S}$ & $145 \mathrm{E}$ & Jan. 1960-Dec. 1967 \\
12 & Port Aux & & & \\
\multicolumn{7}{c}{ Francais } & $49 \mathrm{~S}$ & $70 \mathrm{E}$ & Jan. 1960-Dec. 1967 \\
\hline
\end{tabular}

Table 1 presents a list of stations, their geographic coordinates and the period. of record. Ozone data for each of the stations are arranged according to the lunar days for the entire period of study (date on New Moon represents lunar day 0). The values for the same lunar day are averaged over different lunations. The departures of these averages from the lunar monthly mean are divided by their standard deviations, and the ratios have been subjected to harmonic analyses so that amplitudes and phases of different harmonics are determined. This has revealed two major periodicities, with periods of semi-lunar month and lunar month.

Table 2 Amplitudes and Phases of Lunar and Semi-lunar Cycles in Ozone and Variances explained by Each Compoiıent

\begin{tabular}{|c|c|c|c|c|c|c|c|}
\hline \multirow{2}{*}{ Station } & \multicolumn{2}{|c|}{$\begin{array}{r}\text { Lunar cycle } \\
\text { Phase } \\
\text { (days }\end{array}$} & Semi-lur & $\begin{array}{l}\text { nar cycle } \\
\text { Phase } \\
\text { (days } \\
\text { after }\end{array}$ & \multicolumn{3}{|c|}{ Variance $(\%)$} \\
\hline & litude & $\begin{array}{c}\text { New } \\
\text { Moon) }\end{array}$ & litude & $\begin{array}{l}\text { New } \\
\text { Moon) }\end{array}$ & Lunar & lunar & Total \\
\hline Aarhus & 0.92 & 24.9 & 0.57 & 1.4 & 42.3 & 16.2 & 58.5 \\
\hline Goose Bay & 0.76 & 21.8 & 0.71 & 1.1 & 28.9 & 25.2 & 54.1 \\
\hline Arosa & 0.38 & 18.3 & 0.90 & 2.8 & 7.2 & 40.5 & 47.7 \\
\hline Toronto & 0.57 & 22.3 & 0.47 & -1.4 & 16.2 & 11.0 & 27.2 \\
\hline Tateno & 1.25 & 13.5 & 0.47 & -1.8 & 78.1 & 11.0 & 89.1 \\
\hline Ahmedabad & 0.41 & 3.7 & 1.13 & 1.2 & 8.4 & 63.8 & 72.2 \\
\hline Kodaikanal & 0.90 & 26.8 & 0.50 & 4.4 & 40.5 & 12.5 & 53.0 \\
\hline Gan & 0.67 & 28.7 & 0.98 & -1.3 & 22.4 & 48.0 & 70.4 \\
\hline Huancay.o. & 0.74 & 21.4 & 0.36 & 9.8 & 27.4 & 6.5 & 33.9 \\
\hline Brisbane & 1.13 & 25.0 & 0.43 & 9.2 & 63.8 & 9.2 & 73.0 \\
\hline Aspendale & 1.02 & 22.5 & 0.93 & 7.4 & 52.0 & 43.2 & 95.2 \\
\hline Port Aux. & & & & & & & \\
\hline Francais & 1.00 & 22.8 & 0.50 & -1.7 & 50.00 & 12.5 & 62.5 \\
\hline
\end{tabular}

Table 2 presents amplitudes and phases (days after New Moon) of these oscillations in ozone at all the above stations, and the variances explained by the two components of lunar oscillations. Clearly the maximum amplitude of lunar cycle in ozone occurs around the last quarter and the cycle is weak at Arosa and Ahmedabad. The semi-lunar component of ozone cycle gives maxima near the New Moon and the Full Moon at all the stations except Huancayo, Brisbane and Aspendale, where maxima occur around the first and the last lunar quarters. The semi-lunar cycle in ozone is very weak at Huancayo and Brisbane.
No systematic variation with latitude of either amplitude or phase of these two oscillations is evident. But most of the variance can be explained by these two components alone.

Adderley ${ }^{6}$ reported from analyses of ozone data at Arosa and Canberra that the amount of ozone increases at the vernal equinox about the first and the third lunar quarter and decreases at the same lunar phases at the autumnal equinox, with no effect at mid-winter or mid-summer.

The tidal influence of the Moon on the atmosphere, acting on the scattering particles present in the atmosphere, has been suggested as the cause of the cyclic variations in sky brightness $^{7}$ and in maximum sky polarization ${ }^{8}$. It is possible that this dust might destroy ozone in the atmosphere in the manner suggested by Pittock ${ }^{9}$ to explain a "hole" in ozone profile near 50 mbar level over Fort Collins, producing the observed variations. But this explanation is speculative and requires further investigation of more ozone records at many places before it can be established.

G. M. SHAH

Atmospheric Environment Service,

Department of the Environment, Toronto

Received November 18, 1971.

1 Bradley, D. A., Woodbury, M. A., and Brier, G. W., Science, 137, 748 (1962).

2 Adderley, E. E., and Bowen, E. G., Science, 137, 749 (1962).

3 Bigg, E. K., Nature, 197, 172 (1963).

4 Bowen, E. G., J. Geophys. Res., 68, 1401 (1963).

5 Bigg, E. K., J. Geophys. Res., 68, 1409 (1963).

6 Adderley, E. E., J. Geophys. Res., 68, 1405 (1963).

7 Barber, D. R., J. Atmos. Terr. Phys., 24, 1065 (1962).

8 Dietse, G., J. Atmos. Terr. Phys., 28, 259 (1966).

9 Pittock, A. B., Nature, 207, 182 (1965).

\section{Rate of Horizontal Fault Displacement in New Zealand}

ACCORDING to theories of plate tectonics ${ }^{1}$, a band of concentrated horizontal strain extends from a triple-point junction near $60^{\circ} \mathrm{S} 158^{\circ} \mathrm{E}$ through New Zealand to a triple-point junction near $2^{\circ} \mathrm{S} 128^{\circ} \mathrm{E}$. The region of the band of strain within New. Zealand is known as the Alpine Fault Zone ${ }^{2}$. From seafloor spreading rates and from the known horizontal strain directions on the Alpine Fault Zone, the rate of horizontal strain is estimated to be about $34 \mathrm{~mm}$ per year ${ }^{3,4}$. In the southern part of New Zealand, the fault zone is represented by the dextral Alpine Fault itself, and in the northern part by several subparallel dextral faults that branch off from the Alpine Fault (Fig. 1).

The position of active faults is shown by the displacement of topographic features and is best measured by the displacement of flights of terraces ${ }^{2}$. The faulted terraces have been eroded in late Quaternary gravels, and step down from an aggradational surface at the top of the gravels to the flood plain of the present day river and so they provide a cumulative record of the vertical and strike-slip displacements back to the formation of the aggradation surface. A comparison of the rates of horizontal strain inferred from seafloor spreading and from the displacement of the faults is necessary to know the age either of the aggradation surface itself or of one of the younger terraces.

No material suitable for radiocarbon dating has been found in any of the faulted river terraces, and it has been assumed that cold conditions would lower the forest line, increase erosion, and cause river aggradation. The various ages that have been proposed for the aggradation surface, which range from 35,000 to $15,000 \mathrm{yr}$, are thus mostly those of the cold periods of the late Pleistocene as defined in the northern hemisphere 4 . It now seems that the correct age is $\sim 10,000 \mathrm{yr}$, and that river aggradation was determined not by the height of the forest line 